\title{
THE DIGITAL BANKING IN INDIA-RECENT TRENDS, OPPORTUNITIES
} AND CHALLENGES

\section{Shahabas Ahmed C.B}

Sreeju V. V.*
Assistant Professor (On Contract), P. G. Department of Commerce, Cooperative Arts \& Science College, Madayi, Kannur Dist., Kerala.

Assistant Professor (On Contract), P.G. Department of Commerce, Cooperative Arts \& Science College, Madayi, Kannur Dist., Kerala. ${ }^{*}$ Corresponding Auhtor

ABSTRACT Digital banking has paved way to another spectrum of banking by allowing the customers to conduct their day-to-day banking activities at their convenience. The Digital banking systems in developing countries like India are growing rapidly due to the penetration of internet and mobile phones. Banking transaction scenario has changed rapidly from typical to convenience banking, which offers enormous opportunity to move towards cashless and less cash society. The government of India has taken numerous steps to enhance and embolden digital banking system with a view to promote 'Digital India'. As part of the initiative, the GoI intends to generate a 'digitally empowered' economy that is 'Faceless, Paperless, and Cashless'. In the last few decades, banking system has undergone some distinct phases of digital transformation. This transformation was boosted by rising competition among public sector, private sector and foreign banks, and the goal is to make banking cheaper and efficient and also to access for all of the country's citizens. The objective of this paper is to examine recent trends in digital banking services, benefits, opportunities, hurdles and challenges of Digital Banking System in India. The prime objective behind integrating banking services with technology is undoubtedly convenience; the research article will make a detailed study about the concept and examines the above stated objectives.

KEYWORDS : Digital banking, Digital India.

\section{INTRODUCTION}

Digital banking or Digitalization of a bank has radically altered the landscape of banking in the last few years. Digital technologies which were initially limited to banking channels now encompass the entire banking spectrum. So, whether it is back-end operations or customer facing channels, digital banking delivered through new-age technologies is the way forward for all participants in the financial service industry. India is witnessing a rocket speed boom for the digital age. Our leap into the digital age opens up a sea of opportunities in the banking sector. The shift from traditional forms of banking into digital banking has bought significant changes in the lifestyle of the Indian citizens. The recent trends in the banking and financial sector in India and all these new technologies are predicted to reshape the industry of business and money. Banking sector has undergone distinct phases of digital transformation in the last few decades. The first transformation was a conversion to electronic operations leading to efficiency and automation led model that made banking more transactional and technology-centric. Banks started focusing on improving customer convenience through the use of new innovative technologies. GoI is showing great support with schemes like "Pradhan Mantri Jan Dhan Yojana" and "Digital India", which aims proving a bank account to every citizen and transform India into a digitally empowered society. Meanwhile, the competition from the foreign and private sector banks have strained the government regulators, nationalized banks and financial institutions to adopt advanced technology in order to stay relevant in the race.

\section{Evolution of Digital Banking Services}

Banking sector has undergone three distinct phases of digital transformation in the last few decades. The first transformation was a conversion to electronic operations leading to efficiency and automation led model that made banking more transactional and technology-centric. Banks started focusing on improving customer convenience through the use of ATMs, call-centres, telephone banking.

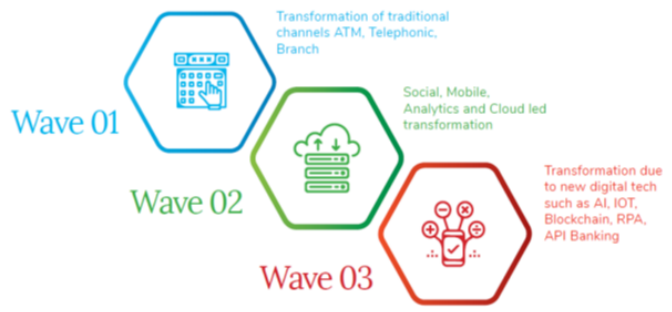

Figure 1: Evolution of Digital Banking

The next wave was fuelled by a range of SMAC technologies (Social, Mobile, Analytics and Cloud) that currently has a visible influence in the banking services and products of today. These technologies allowed financial institutions to move from being just an efficient enabler to a more personalized provider of banking services.

The current wave of digital transformation is being driven by newer technologies such as Artificial Intelligence, Robotic Process Automation, Blockchain, API Banking, and Internet of Things which have the potential to dramatically alter the banking landscape. These technologies, when harnessed together, will be able to provide much deeper levels of personalization and enhanced customer experience, transform the banking operations, changing the very essence of how the banking industry operates today.

\section{Objectives of the Study}

- To highlight the recent trends in digital banking services in India.

- To evaluate the benefits and opportunities of digital banking system in India.

- To identify the hurdles and challenges of digital banking in India.

\section{Research Methodology}

The study is descriptive in nature. The data used for the study is secondary in nature and has been collected from RBI (Reserve Bank of India) bulletin, annual reports of RBI, various 
reference books related to E-Banking, Digital banking, ECommerce, M-Commerce, Information Technology, Marketing, Banking, Finance, Commerce, Management etc,. For the said research study the secondary data is also used from the various National and International Research Journals which are related to Commerce, Management, Marketing and Finance and also collected from various websites.

\section{Review of Literature}

The emergence of new forms of technology had created highly competitive market conditions for bank providers. However, the changed market conditions demand for better understanding of consumers' needs (Beckett, Hewer and Howcroft, 2000). The challenge facing internet banking, in general, is the quality of delivery service - including both delivery speed (i.e., short advance time required in ordering) and delivery reliability (i.e., delivery of items/services on time) (Furst et al., 2000).The Internet banking is changing the banking industry and is having the major effects on banking relationships. Internet banking involves use of Internet for delivery of banking products and services. There are several major challenges and issues facing the internet banking today. First, and perhaps most important is the security concern (Ziqi and Michael, 2003). Limited online payment options have resulted in many customers to drop out due to dissatisfaction and inconvenience. Internet banking also has the potential to create new opportunities for fraud and cyber crime. Moreover, customer education on security risks can play an important role for consumer protection and thereby, limit reputational risk of the banks. Finally, the issue of customer unfamiliarity with the internet is also imperative to deal with, which is prominent among senior citizens (Yang et al., 2007)

\section{Recent Trends in Digital Banking Services in India - Digitization:}

With the rapid development of digital technology, it became necessary for banking and financial services in India to keep up with the changes and develop new digital solutions for the tech-savvy customers. Besides the banking industry, insurance, healthcare, retail, trade, and commerce are some of the major industries that are experiencing the massive digital shift. To stay competitive, it is necessary for the banking industry to take the leap on the digital bandwagon. Modern trends in digital banking system make it easier, simpler, paperless, signature-less and branch-less with numerous features like IMPS (Immediate Payment Service), RTGS (Real Time Gross Settlement), NEFT (National Electronic Funds Transfer), Online Banking, and Tele-banking. Digitization has created the comfort of "anywhere and anytime banking." It has resulted in the cost reduction, improved revenue generation, and reduced human error.

\section{- Mobile banking}

Mobile banking is one of the dominant trends in digital banking industry. The use of a Smartphone to exercise various banking services like checking account balance, money transfer, and bill payments, without the need of visiting the branch. This trend has taken over the conventional banking systems. In few years, mobile banking is expected to become even more efficient and effortless to keep up with the customer demands. Mobile banking future trends hint at the acquisition of IoT(Internet of Things) and Voice-Enabled Payment Services to become the reality of tomorrow. These voiceenabled services can be found in smart TVs, smart cars, smart homes, and smart everything.

\section{- Unified Payments Interface (UPI)}

Unified Payments Interface or UPI is the one of the fastest and most secure payment gateway that has entirely changed the way payments are made. With the use of mobile phone it provides a real-time inter-bank transaction at anytime and anywhere. UPI payment system is considered as the future of retail banking in India. UPI is developed by National Payments Corporation of India and regulated by the Reserve Bank of India. This revolutionary transactions system is launched in 2016. This system makes funds transfer available $24 x 7,365$ days unlike other internet banking systems. There are approximately more than 40 apps and 50 banks supporting UPI transaction system. In the postdemonetization India, this system played a significant role. Banking is expected to become more "open" with the help of UPI in the near future.

\section{- Blockchain}

Blockchain is the new buzzword in the digital world. It is said to be the future technology of banking and financial services that works on the principles of computer science, data structures and cryptography and is the core component of cryptocurrency. Without the ability to modify it, Blockchain uses technology to create blocks to process, verify and record transactions. Niti Aayog is creating India's largest Blockchain network named IndiaChain, which is expected to transform several industries, minimize the chances of fraud, improve transparency, accelerate the transaction process, less human intervention and build an unhackable database. Several aspects of banking and financial sector like payments, clearance and settlement systems, stock exchanges and share markets, trade finance, and lending are predicted to be impacted by the introduction of IndiaChain network.

\section{- Chatbots}

Chatbots is one of the emerging trends in the Indian banking sector. As assistance in customer support services, several private and nationalized banks in India have started to adopt chatbots or Artificial intelligence robots. For now, the use of this technology is at a budding stage and usage of that is expected to grow in the near future. Banks and financial institutions are expected to adopt more chatbots with the higher level of intelligence for improved customer interaction and personalized solutions. The technology will reduce the chances of human error and convey accurate solutions for the customers. Also, it can identify fraudulent behavior, collate surveys and feedback and assist in financial decisions.

\section{- Fintech Companies}

Financial Technology companies are ones that lead technology to the world of banking and industry. Fintech companies have become an important part of the financial services sector in India. In the past few decades, huge investment has been made in these companies and it has emerged into a multi-billion-dollar industry globally. Fintech companies and fintech apps have changed the way financial services are provided to the customers.. Some important names that have made an impact include Paytm, PhonePe, Policy Bazaar, MobiKwik, Shubh Loans, Lending Kart, PayU, Kissht and Faircent. Fintech companies have led to a massive improvement in financial services, customer experience, and reduced the price paid. According to a report by National Association of Software and Services Companies (NASSCOM), things will continue to look up with fintech market in India potentially touching 2.4 billion dollar by 2020 .

\section{- Digital-Only Banks}

We cannot ignore recent trend in the Indian financial system. Digital-only banks This is a new breed of banking institutions that have emerged to create paperless and branch-less banking systems.. These banks provide banking facilities only through various internet platforms that can be accessed on mobile phones, computers, and tablets. It provides most of the basic services to the customers in the most simplified manner and gives access to real-time data at anytime. The growing popularity of these Digital-only banks is said to be a real 
threat to traditional banks. ICICI Pockets is India's first digitalonly bank. Though virtually, these banks are attractive to the customers because they provide high-speed banking services at very transaction fees. They alleviate the need of visiting the bank and standing in a queue, in today's fast lane life these banks suit the customer needs in best possible manner.

\section{- Cloud Banking}

Cloud Banking has taken the banking world by storm. It seems the technology will soon find its place in the banking and financial services sector in India. Cloud computing will organize and improve banking and financial activities. Use of cloud-based technology means improved data security, improved flexibility and scalability, increased efficiency, faster services, solution, easier integration of newer technologies and applications. In addition, the banks will not have to invest in expensive software and hardware as updating the information is easier on cloud-based banking models.

\section{- Wearable Technology}

With the development smartwatch technology, the banking and financial services technology is also aiming to develop wearables for retail banking customers and in which provide more control and easy access to their account. Wearables have entirely changed the way of performing our daily activities. Therefore, this technology is expected to be the trend in the future retail banking by providing major banking services with just a click on a user-friendly interface on their wearable device.

\section{- Biometrics}

Essentially for security reasons, a Biometric Authentication system is altering the national identity policies and the impact is expected to be extensive. Banking and financial services are just one of the many other industries that going to experience the impact. With a combination of encryption technology and OTPs, biometric authentication is forecasted to create a highly-secure database protecting it from leaks and hackers attempts. To ensure sophisticated security to customers' account and capital financial institutions in India are exploring the potential of this powerful technology.

\section{Benefits and Opportunities of Digital Banking System in India}

\section{- Internet Penetration}

Most of the telecom companies in India offering affordable data tariff packages for the last recent years after the launch of Reliance Jio which were started with unbelievable data offers. According to the Market research agency Kantar IMRB, India's internet users expected to register 62.7 crores in 2019, driven by rapid internet growth in rural areas. The increasing number internet users in India open up a sea of opportunities for digital banking industry. They should utilise this opportunity by offering modern and innovative banking services at reasonable cost to attract more internet users to adopt digital banking services.

\section{- Usage of Smart phone}

Smart phone have become like an organ for the human beings. In the recent times it becomes one of the essential parts of our daily life. According to a joint study by Associated Chambers of Commerce and Industry of India and PwC, the number of smartphone users in India expected to rise by $84 \%$ to 85.9 crores by 2022 . With the help mobile applications of banker, customers can handle bank account at their finger tips. Both volume and value of mobile banking are significantly growing. Besides websites, most of the banks in India developed their own advanced mobile applications to facilitate easy and quick transactions.

\section{- Initiatives of Government}

Government of India with a vision to transform India into a digitally empowered society and knowledge economy, govt. initiated programs such as Pradhan Mantri Jan Dhan Yojana and Digital India, led to the development of economy by way of financial inclusion. The government has asked all departments to enable electronic payment options such as Bhim-UPI QR code at their cash counters as part of plans to boost digital transactions. Now almost all the payments to government such as taxes, duties even fines also started collect through digital mode.

\section{- Digital Banking Solutions}

GoI and RBI are encouraging the emergence of innovative digital banking solutions like fintech start-ups. Fintech startups pave a way for a financially smart India with global recognition. According to NASSCOM, things will continue to look up with Indian fintech market potentially touching 240 crores by 2020 . To add to the ongoing momentum and scale heights, fintech ecosystem will have to innovate and specialise in key sectors. That seems most plausible and promising with intelligent automation, artificial intelligence and blockchain.

\section{- E-Commerce}

Ecommerce allows people to carry out businesses without the barriers of time or distance. One can log on to the internet at any point of time, be it day or night and purchase or sell anything one desires at a single click of the mouse. Intensification of Ecommerce highly contributing towards digital transactions. Digital banking has several other benefits. Users can shop online, buy tickets, make advanced bookings, etc.

\section{Untapped Rural Market}

As India second largest populous country and the $3 / 4$ population lives in rural areas and there is a proper need to divert the efforts the entire areas city as well as villages. The Indian government seeks to digitize banking in rural areas, as an attempt to bring the entire country into the Digital Era. Increasing the use of cashless transactions in rural villages has the potential to alleviate cash-based crimes (e.g. bribes, robbery). Digital banking helps to create a safer space and more financial freedom within rural areas.

\section{Challenges and Hurdles of Digital Banking System in India - Lack of Digital Literacy}

For the senior and uneducated people the digital transformation is a problematic affair. In India the literate people is only moderate, in which only a meager population posses digital literacy. They are afraid of perform digital transaction due to lack of knowledge and fear of making errors, because a minor error result in huge financial loss. Without adequate knowledge there is no digital transformation from cash to cashless economy.

\section{- Cash Dependent Economy}

India's more than half of the populations are below poverty line, unbanked and unorganized. Majority of the Indians depends on cash based transaction because they feel more convenience and safety in handling cash dealing. The rural Indian people are not well aware of digital mode of banking transaction due lack of modern technology and illiteracy.

\section{- Privacy risk:}

The risk of disclosing private information \& fear of identity theft is one of the major factors that inhibit the consumers while opting for digital banking services. Most of the consumers believe that using online banking services make them vulnerable to identity theft. According to the study consumers worry about their privacy and feel that bank may invade their privacy by utilizing their information for marketing and other secondary purposes without consent of consumers. 
- Security Risk:

The problem related to the security has become one of the major concerns for banks. A large group of customers refuses to opt for digital banking facilities due to uncertainty and security concerns. Most of internet users are not using digital banking in India because of security concerns. So it's a big challenge for marketers and makes consumers satisfied regarding their security concerns, which may further increase the digital banking use.

\section{- Stiff Competition:}

The nationalized banks and commercial banks have the competition from foreign and new private sector banks. Competition in banking sector brings various challenges before the banks such as product positioning, innovative ideas and channels, new market trends, cross selling ad at managerial and organizational part this system needs to be manage, assets and contain risk. Banks are restricting their administrative folio by converting manpower into machine power i.e. banks are decreasing manual powers and getting maximum work done through machine power. Skilled and specialized man power is to be utilized and result oriented targeted staff will be appointed.

\section{- Low Internet Penetration:}

The digital banking transaction and internet service has evolved over the years. For the development of cashless economy broadband and internet connection and its bandwidth should be improved and provided at an affordable cost. Most of the cities were enriched with providing free WiFi services even at railway and metro stations, shopping malls and cinema theatres. But still the knowledge and availability of internet in rural India is still a one of the biggest challenges faced by digital banking industry. So the penetration of internet and knowledge related to internet are major hurdles that can be overcome with the joint effort of various stakeholders.

\section{- Managing Technology:-}

Developing or acquiring the right technology, deploying it optimally and then leveraging it to the maximum extent is essential to achieve and maintain high service and efficiency standards while remaining cost effective and delivering sustainable return to shareholders. Early adopters' of technology acquire significant competitive advances Managing technology is therefore, a key challenge for the Indian banking sector.

\section{- Difficult for First Timers}

For a first time user, navigating through a website of an internet bank may be hard and may take some time. Opening an account could also take time as some sites ask for numerous personal details including a photo identification which can inconvenience the potential customer. Because of this complexity, they may be discouraged to use this internet banking service. Tutorials and live customer support may be provided, though, to help the client in his or her needed tasks so it's best to take the time to know the virtual environment.

\section{- Cyber Crime}

The cyber security is the major issue in the field of digital banking. Most banking and financial applications are subject to cyber fraud or cyber-attacks. Obviously, the reason is money being the unquestionable objective. Hackers have been known to be innovative in their endeavors to stealing funds, either as large amounts or minuscule amounts from thousands of accounts, over a long period of time. If not money directly, there is always the threat of customers data is being compromised. According to the IAMAI Reports, most of the internet users are not using internet banking in India because of security concerns.
- Regulation and Legalities

Digital banking services makes it possible for banks and their customers to do business from anywhere in the world. This greatly increases potential client base of banks. Nevertheless all Business, the global approach to banking that internet banking permit makes it extremely difficult for regulatory authorities to enforce finance laws. Additionally, regulations differ from nation to nation and banks are not always proficient in the financial laws for every nation in which they have business. The lack of proficiency opens banks and their clients up to law violations and lawsuits

\section{- Sustainability}

An organization can attain sustainability as a leader is possible only through synergy. Only when the users acknowledge the value of the product or service will the organizational value skyrocket to success and remain there. In the digital banking context, the power of social media is often overlooked. While consistently good reviews uplift the organization to a better status, consistently bad reviews can destroy even an entire empire.

\section{CONCLUSION}

In the past few years, the Indian banking sector has completely transformed to another spectrum. The banks are facing many challenges and many opportunities in current digital banking scenario. The main objectives behind integrating banking services with technology are, convenience efficiency and transparency. Technology has now become familiar to most individuals, to an extent that it influences their lifestyle. Many financial innovations like UPI, Internet Banking, Mobile Banking, Mobile Wallet, QR Code etc. have completely changed the face of Indian banking. The opportunities can availed efficiently and the challenges can be easily counter balanced by adopting more innovative solutions and technological, security measures.

\section{REFERENCES}

1. Dr. Lekshmi Bhai.P.S (2018), E-Banking in India - Problems and Prospects International Journal of Current Engineering and Scientific Research (IJCESR), ISSN (PRINT): 2393-8374, (ONLINE): 2394-0697, VOLUME-5, ISSUE1, PP 77-81.

2. C. B. Pavithra and Dr. A. C. 'Digital Payment System- Benefits, Hurdles, Oppurtunities and Challenges in India', An International Multidisciplinary Quarterly Research journal, ISSN 2277-5730, Volume- VIII Isssue- I, Part I, PP 65-76

3. RanganayakiSriram Devulapalli and Sai Karthik Oruganti, 'Challenges and Opportunities of e-Banking in India', IOSR Journal of Business and Management (IOSR-JBM) e-ISSN: 2278-487X, p-ISSN: 2319-7668 PP 56-61.

4. Nancy Syan (2018), 'Emerging Trends in Banking Sector in India with Special Reference to Digitization', Abhinav National Monthly Refereed Journal of Research in Commerce \& Management, Online Issn-2277-1166, Volume 7, Issue 1, PP 76-81.

5. https://www.rbi.org.in/

6. https://www.enterpriseedges.com/

7. https://economictimes.indiatimes.com/ 